\title{
Rapid screening for antibiotic resistance elements on the RNA transcript, protein and enzymatic activity level
}

\author{
Alexander Rohde ${ }^{1,2^{*}}$, Jens Andre Hammerl ${ }^{1}$ and Sascha Al Dahouk ${ }^{1}$
}

\begin{abstract}
Background: The emerging threat posed by antibiotic resistance has affected public health systems all over the world. Surveillance of resistant bacteria in clinical settings and identifying them in mixed cultures is of paramount importance and can contribute to the control of their spreading. Culture-independent monitoring approaches are highly desirable, since they yield results much faster than traditional susceptibility testing. However, many rapid molecular methods like PCR only detect the sole presence of a potential resistance gene, do not provide information regarding efficient transcription, expression and functionality and, in addition, cannot assign resistance genes to species level in mixed cultures.
\end{abstract}

Methods: By using plasmid-encoded TEM $\beta$-lactamase mediated ampicillin resistances as a proof of principle system, we (1) developed a fluorescence in situ hybridization-test (FISH) capable to detect the respective mRNAs, (2) implemented an immunofluorescence test to identify the corresponding proteins and (3) compared these two microscopic tests with an established colorimetric nitrocefin assay to assess the enzymatic activity.

Results: All three methods proved to be suitable for the testing of antibiotic resistance, but only FISH and immunofluorescence were able to differentiate between susceptible and resistant bacteria on the single cell level and can be combined with simultaneous species identification.

Conclusions: Fluorescence in situ hybridization and immunofluorescence tests are promising techniques in susceptibility testing since they bridge the gap between the slow, but accurate and sound cultural methods and molecular detection methods like PCR with much less functional relevance.

Keywords: Antibiotic resistance, Fluorescence in situ hybridization, $\beta$-Lactamases, Plasmids

\section{Background}

The emergence of antibiotic resistance is threatening the public health in industrialized as well as developing countries, resulting in therapy failure and increased health-care expenditures $[1,2]$. Monitoring the occurrence of antibiotic resistance is one important component to control its spreading and, consequently, numerous surveillance programs have been implemented [3-6]. The susceptibility of bacterial isolates towards certain antimicrobials is mainly assessed by slow cultural

\footnotetext{
*Correspondence: alexander.rohde@bfr.bund.de

${ }^{1}$ Department of Biological Safety, Federal Institute for Risk Assessment, Diedersdorfer Weg 1, 12277 Berlin, Germany

Full list of author information is available at the end of the article
}

methods, which require the availability of pure isolates. However, in clinical settings rapid susceptibility testing is extremely crucial to initiate appropriate therapeutic measures because any delay might increase morbidity, mortality and long-term sequelae; therefore, alternative testing methods are gaining importance in hospital care [7]. Screening ubiquitous biofilms in hospitals consisting of multiple different bacterial species or blood samples containing mixed cultures for resistance genes can be carried out by PCR-testing; however, detected resistance genes can neither be attributed to a specific species, nor can it prove a functional resistance. Therefore, cultureindependent assays on the single cell level, preferably coupled with the simultaneous species identification, are 
highly desirable, not only for academic purposes, but also in clinical or environmental microbiology. $\beta$-lactamases are one of the most frequently encountered mediators of antimicrobial resistance. Among them, TEM $\beta$-lactamases encoded on plasmids represent especially interesting targets because mobile elements like plasmids can easily spread antibiotic resistance. To detect the presence of these resistance elements, three cultureindependent methods appear to be capable of fulfilling this task. Firstly, the detection of TEM $\beta$-lactamase mRNA transcripts can be performed by a modified version of fluorescence in situ hybridization (FISH), which was initially developed for eukaryotes and has recently also been successfully used for prokaryotes [8-10]. Previous attempts using FISH were mainly restricted to detect single mutations in the highly abundant rRNAs conferring resistance to antibiotics targeting ribosomes, e.g. macrolides [11, 12]; however, by applying dozens of probes simultaneously (instead of only one) mRNAs with much lower concentrations can be detected as well. In parallel with mRNA detection, FISH can be used to simultaneously identify the bacterial species based on their ribosomal RNA [7, 11]. Secondly, immunofluorescence stainings of the proteins with specific antibodies represent a further alternative and can also be used for concurrent species identification [13]. Thirdly, chromogenic substrates like nitrocefin offer a way to test the enzymatic activity of TEM $\beta$-lactamases $[14,15]$. Apart from these methods, reverse transcription PCR assays (RT-PCR) are an additional possibility enabling the detection of efficient transcription [16-18]. However, in contrast to FISH and immunofluorescence stainings, RTPCR cannot detect resistance elements on the single cell level. In this work, we established a FISH assay to detect TEM mRNAs encoded on different kind of plasmids and, additionally, an immunofluorescent staining to detect the corresponding proteins and compared these methods with the traditional nitrocefin assay to screen for functional $\beta$-lactamases.

\section{Methods}

\section{Strains and cultivation}

Escherichia coli strain DH5 $\alpha$ carrying either the high copy number plasmids pLitmus38 (AMP ${ }^{\mathrm{r}}$ ) and pUC18 $\left(\mathrm{AMP}^{\mathrm{r}}\right)$ or the medium copy number vector pBR328 $\left(\mathrm{AMP}^{\mathrm{r}}, \mathrm{TET}^{\mathrm{r}}, \mathrm{CHL}^{\mathrm{r}}\right.$ ) with a low plasmid stability were used as well as the E. coli reference strain ATCC 35218, a reference strain producing TEM-1 $\beta$-lactamases [1921]. On the plasmids pLitmus 38 , pUC18 and pBR328 a TEM-1 gene confers resistance towards ampicillin. Susceptibility of these bacterial strains was tested by Etest $^{\mathbb{B}}$ (bioMerieux, France) according to manufacturer specifications and all $\mathrm{AMP}^{\mathrm{r}}$ E. coli strains possessed MICs $>256 \mu \mathrm{g} / \mathrm{ml}$. As negative controls, DH5 $\alpha(\mathrm{MIC}<1.5 \mu \mathrm{g} / \mathrm{ml})$ and GeneHogs $(\mathrm{MIC}<2 \mu \mathrm{g} / \mathrm{ml}$; Thermo Fisher Scientific, USA) without plasmids were used as susceptible E. coli strains as well as Y. pseudotuberculosis ATCC 29833 (MIC $<0.125 \mu \mathrm{g} / \mathrm{ml}$ ). Two clinical Klebsiella pneumoniae isolates, $\mathrm{K} 2$ with an intermediate resistance (MIC $<24 \mu \mathrm{g} / \mathrm{ml}$ ) and the highly resistant strain My6107 (MIC >256 $\mathrm{\mu g} / \mathrm{ml}$ ), and Yersinia enterocolitica DSM 13030 (MIC $>256 \mu \mathrm{g} / \mathrm{ml}$ ) were used as ampicillin-resistant strains expressing non-TEM $\beta$-lactamases. E. coli and $K$. pneumoniae were grown in LB medium at $37^{\circ} \mathrm{C}$, Y. enterocolitica and Y. pseudotuberculosis at $28^{\circ} \mathrm{C}$. To exhibit antibiotic stress, bacterial cultures were grown in LB medium containing ampicillin in a concentration of $100 \mu \mathrm{g} / \mathrm{ml}$.

In addition, $25 E$. coli isolates from different environmental samples and with different TEM-variants (Additional file 1: Figure S1) were used to verify the inclusivity and sensitivity of the established FISH and immunofluorescence assays. To test whether the newly developed assays are applicable for mixed bacterial cultures, samples containing different species (Salmonella enterica, thermophilic Campylobacter spp., Listeria spp., Y. enterocolitica, E. coli O157) were prepared as described earlier [22].

\section{Fish}

Bacterial cultures were fixed by adding three volumes of $4 \%$ (vol/vol) PBS/formaldehyde mixture (Carl Roth, Germany). Samples were incubated for $2 \mathrm{~h}$ at $4{ }^{\circ} \mathrm{C}$ and then washed three times by centrifugation and resuspension in PBS. Cells were resuspended in a 50 \% Ethanol/ PBS (vol/vol) mixture and either used directly or stored at $-20{ }^{\circ} \mathrm{C} .10 \mu \mathrm{l}$ of each sample were pipetted on glass slides (miacom ${ }^{\circledR}$ diagnostics, Germany), dried shortly on a $52{ }^{\circ} \mathrm{C}$ hot plate (miacom ${ }^{\circledR}$ diagnostics) and dehydrated in 50, 80 and $96 \%$ ethanol for 3 min each. The slides were coated with $10 \mu \mathrm{l}$ hybridization buffer $(1 \mathrm{M} \mathrm{NaCl}, 20 \mathrm{mM}$ Tris- $\mathrm{HCl}$ (pH 7.2), $0.01 \%$ SDS, $15 \%$ formamide) containing FISH probes in an accumulated concentration of $800 \mathrm{nM}$ (or approximately $20 \mathrm{nM}$ for each FISH probe). FISH probes hybridized in a light-protected humidity chamber at $30{ }^{\circ} \mathrm{C}$ for at least $1.5 \mathrm{~h}$. Slides were rinsed in distilled cold water for a few seconds, followed by washing for $10 \mathrm{~min}(310 \mathrm{mM} \mathrm{NaCl}, 20 \mathrm{mM}$ Tris- $\mathrm{HCl}$ (pH 7.2), $0.01 \% \mathrm{SDS}$ ) at $30{ }^{\circ} \mathrm{C}$. Slides were again rinsed twice in distilled water, immediately air-dried and embedded in Roti $^{\circledR}$-Mount FluorCare DAPI (Carl Roth). FISH probes were designed with the Stellaris Probe Designer and synthesized and labelled with CalFluor Red 610 by Biosearch Technologies (Petaluma, USA). The bla-gene of pBR328 (GenBank accession \#: L08858.1) was used to construct the FISH probes as listed in Table 1. A conventional 
Table 1 Oligonucleotides used to detect TEM mRNA and Enterobacteriaceae (as a positive hybridization control)

\begin{tabular}{|c|c|c|c|}
\hline Probe name & Sequence $\left(5^{\prime} \rightarrow 3^{\prime}\right)$ & Target & Detection purpose \\
\hline Enterobac-Alexa488 & TCGTGTTTGCACAGTGCTGTGTTT & 23S rRNA & $\begin{array}{l}\text { Enterobacteriaceae (adapted with minor modifications } \\
\text { from Bohnert et al. [23]) }\end{array}$ \\
\hline Enterobac-Komp & TCGTGTTTGCAGAGTGCTGTGTTT & 23S rRNA & $\begin{array}{l}\text { Competitor for Enterobacteriaceae detection } \\
\text { (adapted with minor modifications from Bohnert et al. } \\
\text { [23]) }\end{array}$ \\
\hline Bla-TEM-CalFluor610 & $\begin{array}{l}\text { GGAAATGTTGAATACTCAT } \\
\text { AAAAGGGAATAAGGCGAC } \\
\text { CAGGAAGGCAAAATGCCGC } \\
\text { GCGTTTCTGGTGAGCAAA } \\
\text { CAGCATCTTTTACTTTCAC } \\
\text { CTCGTGCACCCAACTGATC } \\
\text { GATCCAGTTCGATGTAACC } \\
\text { CAAGGATCTTACCGCTGTT } \\
\text { GTTCTTCGGGGGAAAACT } \\
\text { AAGTGCTCATCATTGGAAA } \\
\text { CGCCACATAGCAGAACTTT } \\
\text { CGTCAACACGGGATAATAC } \\
\text { GACCGAGTTGCTCTTGCCC } \\
\text { TCTGAGAATAGTGTATGCG } \\
\text { GTGAGTACTCAACCAAGTC } \\
\text { TAAGATGCTTTTCTGTGAC } \\
\text { CTCTTACTGTCATGCCATC } \\
\text { TTATGGCAGCACTGCATAA } \\
\text { CCGCAGTGTATCACTCAT } \\
\text { TCGTTGTCAGAAGTAAGTT } \\
\text { TTAGCTCCTTCGGTCCTCC } \\
\text { CCATGTTGTCAAAAAAGC } \\
\text { CAAGGCGAGTTACATGATC } \\
\text { TCAGCTCCGGTTCCCAACG } \\
\text { CGTCGTTTGGTATGGCTTC } \\
\text { CAGGCATCGTGGTGTCACG } \\
\text { GCAACGTTGTTGCCATTGC } \\
\text { GTTCGCCAGTTAATAGTTT } \\
\text { GCCGGGAAGCTAGAGTAAG } \\
\text { CCATCCAGTCTATTAATTG } \\
\text { GTCCTGCAACTTTATCCGC } \\
\text { GAAGGGCCGAGCGCAGAAG } \\
\text { CAGCAATAAACCAGCCAGC } \\
\text { GCTCACCGGCTCCAGATTT } \\
\text { CAATGATACCGCGAGACCC } \\
\text { TAACTACGATACCCGGGGCGGGG } \\
\text { TATGACTCCCCGTCGTGTA } \\
\text { CATTCGTTCATCCATAGT } \\
\text { ACCAATCTCAGCGATCTG } \\
\text { TCATATCAGTGA }\end{array}$ & mRNA & TEM $\beta$-lactamase mRNA \\
\hline
\end{tabular}

FISH probe developed by Bohnert et al. targeting the ribosomes of Enterobacteriaceae (Enterobac and the unlabeled competitor Enterobac-Komp) was used as a positive hybridization control (Table 1; [23]). FISH probe lyophilisates were diluted in distilled water and stored at $-20{ }^{\circ} \mathrm{C}$ until usage. Each bacterial strain was tested in three independent hybridization experiments.

\section{Immunofluorescence}

Bacterial cultures were prepared as described for FISH. After drying on a glass slide, the bacteria were permeabilized with lysozyme (Carl Roth, $10 \mathrm{mg} / \mathrm{ml}$ ) for $7 \mathrm{~min}$ and afterwards rinsed shortly with water. Samples were then blocked with blocking buffer [2\% of bovine serum albumin in PBS (Sigma-Aldrich, USA)] for $1 \mathrm{~h}$ at room temperature. Subsequently, the primary antibody [anti(TEM) $\beta$-lactamase ab12251 (mouse); abcam, United Kingdom], diluted 1:200 in blocking buffer, was added and incubated either overnight at $6{ }^{\circ} \mathrm{C}$ (for sequential stainings) or $1 \mathrm{~h}$ at room temperature. Slides were rinsed shortly with water and washed three times with PBS and, finally, with blocking buffer for $3 \mathrm{~min}$ each. Slides were then incubated with the secondary antibody (goat antimouse IgG-Alexa Fluor ${ }^{\circledR} 488$ ab150117, abcam), diluted 
1:300 in blocking buffer, for $1 \mathrm{~h}$ at room temperature. Slides were again rinsed shortly with water and washed three times with PBS for 3 min each, once more rinsed with water, air-dried and embedded in $\operatorname{Roti}^{\circledR}$-Mount FluorCare DAPI. Each bacterial strain was stained in three independent immunofluorescence assays.

\section{Fluorescence microscopy}

Microscopy was carried out with an AxioScope fluorescence microscope using a $100 \times \mathrm{N}$-achroplan Ph3 M27 oil objective (Zeiss, Germany). Images were acquired by the AxioCam MRm and further processed for overlay of different fluorophore channels by using the imaging software ZEN 2012 (Zeiss).

\section{Nitrocefin assay}

Nitrocefin (Merck Millipore, Germany) was dissolved in DMSO (PanReac Applichem, Germany) in a concentration of $5 \mathrm{mg} / \mathrm{ml}$. $50 \mu \mathrm{l}$ of this stock solution was added to $950 \mu \mathrm{l} \mathrm{PBS} .50 \mu \mathrm{l}$ of this nitrocefin working solution was added to $150 \mu \mathrm{l}$ of a bacterial culture. Alternatively, a colony was picked from an agar plate and suspended in $50 \mu \mathrm{l}$ nitrocefin working solution on a glass slide. A colour change from yellow to red was considered as proof for functional $\beta$-lactamases. Each bacterial strain was tested three times.

\section{Results and discussion}

The FISH assay proved to be sensitive enough to detect signals in all TEM $\beta$-lactamase producing strains. FISH signals were highly specific and showed no hybridization with susceptible $E$. coli strains without plasmids conferring resistance or with species which possess other types of $\beta$-lactamases (Additional file 2: Figure S2). Interestingly, the transcription pattern varied among individual cells of a pure culture (Fig. 1a) and depended on the tested plasmids as well as on the growth phase: E. coli strains harbouring pLitmus 38 and pUC18 showed significantly stronger signals than E. coli ATCC 35218 or strains with pBR328. In addition, stationary cultures exhibited stronger FISH signals than exponentially growing cultures, which might be a result of a slower metabolism or prolonged mRNA half-lives. The FISH assay could be easily combined with conventional rRNA-FISH for bacterial identification, as exemplified by the simultaneous use of the FISH probe Enterobac. Notably, not all cells which were stained via conventional ribosome FISH staining showed detectable transcription rates of the TEM $\beta$-lactamase (Fig. 1a), which can be explained with a natural variation in the transcription rates on the single cell level, a phenomenon which has been observed for other mRNAs before $[9,10]$. In contrast to the ribosome staining by the conventional FISH probe Enterobac, the mRNA signal was not evenly distributed throughout the bacterial cell. Instead, several distinct foci can be observed (Fig. 1a), which is in accordance with previously published reports about mRNA distribution in prokaryotes $[9,10]$.

Immunofluorescence staining of the TEM $\beta$-lactamase protein showed a more even signal distribution among the bacterial cells than the RNA-signals determined by mRNA FISH (compare Fig. 1a, b). Stationary cultures also showed stronger signals compared to exponentially growing bacteria. As expected for a protein which is secreted in the periplasm, ring-shaped halo-like structures around the cells were observed, especially for pUC18 E. coli strains (Fig. 1b, right), whereas strains harbouring pLitmus 38 and pBR328 as well as E. coli ATCC 35218 showed protein accumulations mainly in the cell poles (Fig. 1b, left). In accordance with FISH, antibody staining produced stronger signals for pLitmus38 and pUC18 than for pBR328 and E. coli ATCC 35218. Bacteria without a TEM gene were not stained by immunofluorescence (Additional file 3: Table S1).

To elucidate the correlation between transcription and protein level, a sequential FISH and immunofluorescence staining was performed (Fig. 2). However, a clear association between both signals could not be inferred. Some cells showed a pronounced immunofluorescence signal, thus detectable amounts of protein, but a negative FISH signal (thus no detectable mRNAs) or vice versa.

To verify that both assays can be applied to environmental samples, 25 E. coli strains with different TEMvariants (TEM-1, TEM-30, TEM-52) were tested. All 25 isolates were detected by immunofluorescence and showed protein accumulations mainly in the cell poles. However, four strains exhibited a rather weak antibody staining. Likewise, the FISH signals of two strains were too weak to be reliably detected (Additional file 1: Figure S1). However, a combination of both methods enabled clear results. This combined testing might be useful to avoid false-negative results and is especially advisable if samples with strong background fluorescence are examined like food matrices or filtrates [22, 24].

To demonstrate that the detection of antibiotic resistance in samples with many different species is possible, mixed microbial cultures were prepared containing a resistant E. coli strain as well as Listeria spp., Campylobacter spp. and Enterobacteriaceae like Y. enterocolitica, S. enterica and susceptible E. coli (all without TEM-elements). Both methods, FISH and immunofluorescence, reliably identified resistant bacteria within this mixture (Fig. 3).

The nitrocefin assay is an established general assay to identify the presence of most types of $\beta$-lactamase producing strains. All E. coli strains with the high copy 


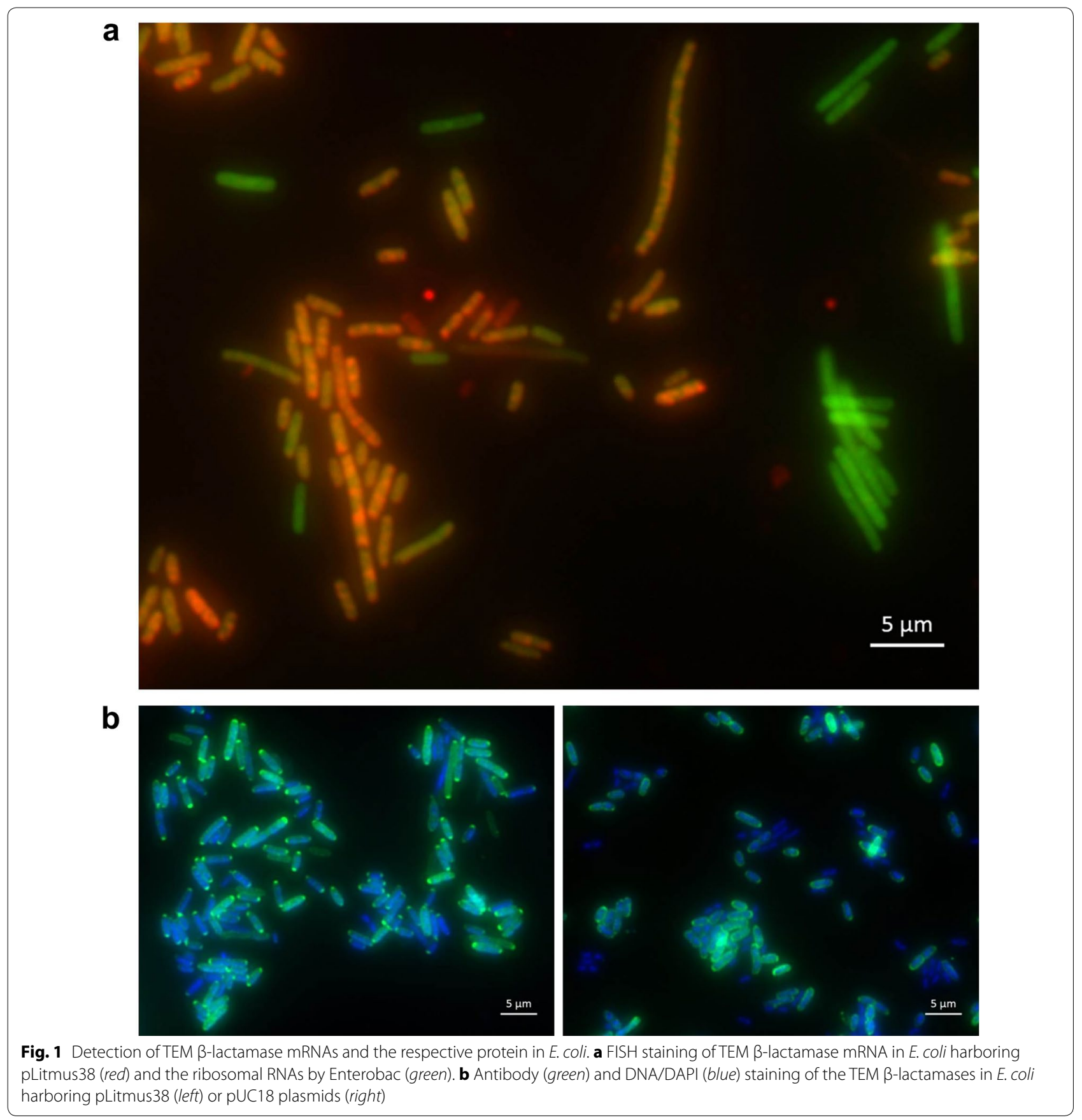

number plasmids pUC18 and pLitmus 38 as well as $K$. pneumoniae My6107 were rapidly tested positive for $\beta$-lactamase in a few minutes, both by colony smear as well as in liquid cultures, whereas all susceptible strains produced negative results (Additional file 4: Figure S3). Interestingly, the colour change for $Y$. enterocolitica, $K$. pneumoniae K2, E. coli ATCC 35218 and strains harbouring the plasmid pBR328 with a low stability and a relatively weak $\beta$-lactamase production [20] was less pronounced, especially in liquid cultures without selection pressure, and took significantly longer than for the resistant $E$. coli strains with high copy plasmids, which showed a much more rapid substrate turnover (Additional file 4: Figure S3). We also tried to use nitrocefin to visualize $\beta$-lactamase activity on the single cell level. However, nitrocefin was not retained within the periplasm and was, thus, unable to distinguish resistant from susceptible cells using microscopy. It has to be noted that 


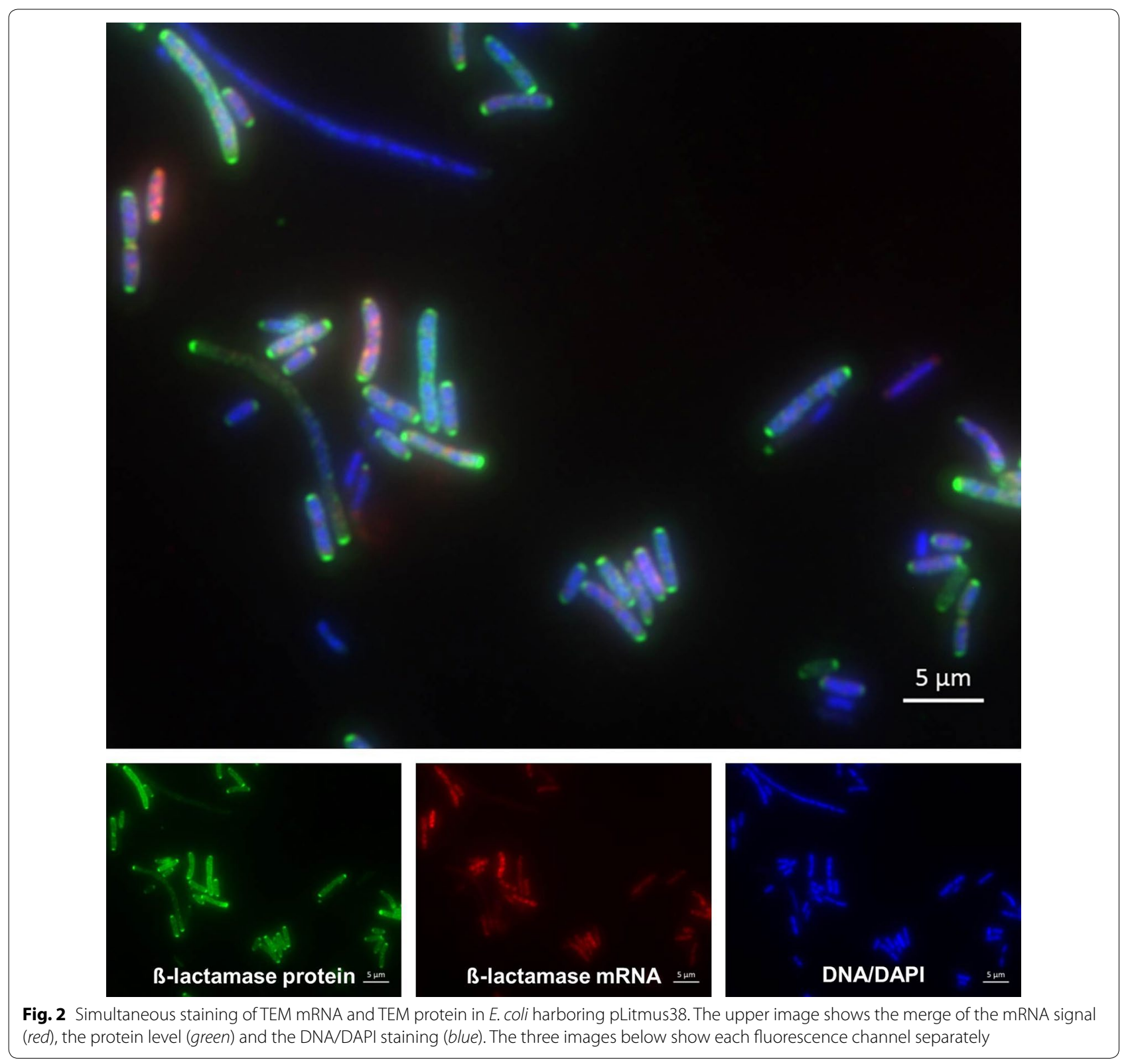

also fluorogenic $\beta$-lactamase substrates like CCF2-AM are available, but these substrates are much more expensive and their application is mainly limited to eukaryotic reporter gene assays.

In summary, all three methods are able to detect antibiotic resistance, in particular in case of constitutive moderate transcription and expression rates, and produce congruent results with regard to signal strength. However, there are intrinsic strength and weaknesses of each technique (Table 2). The fast, affordable and easy nitrocefin activity assay can sense the presence of a broad range of $\beta$-lactamases and is not confined to TEM-like proteins. In addition, detecting biological activity is probably the most meaningful way to search culture-independently for antibiotic resistance. However, nitrocefin is hardly suitable for single cell microscopy, is not very sensitive in the presence of only low numbers of resistant bacteria and, in contrast to FISH and immunofluorescence, cannot be used for the simultaneous species identification on the single cell level. The $\beta$-lactamase antibody staining proved to be a highly convenient and robust system, yielding strong and specific signals. However, it is the slowest of all three methods and depends on the availability of suitable (and rather costly) antibodies. Mutations, which are frequent events in the evolution of antibiotic resistance genes, might easily compromise antibody binding. Finally, multi-probe mRNA 

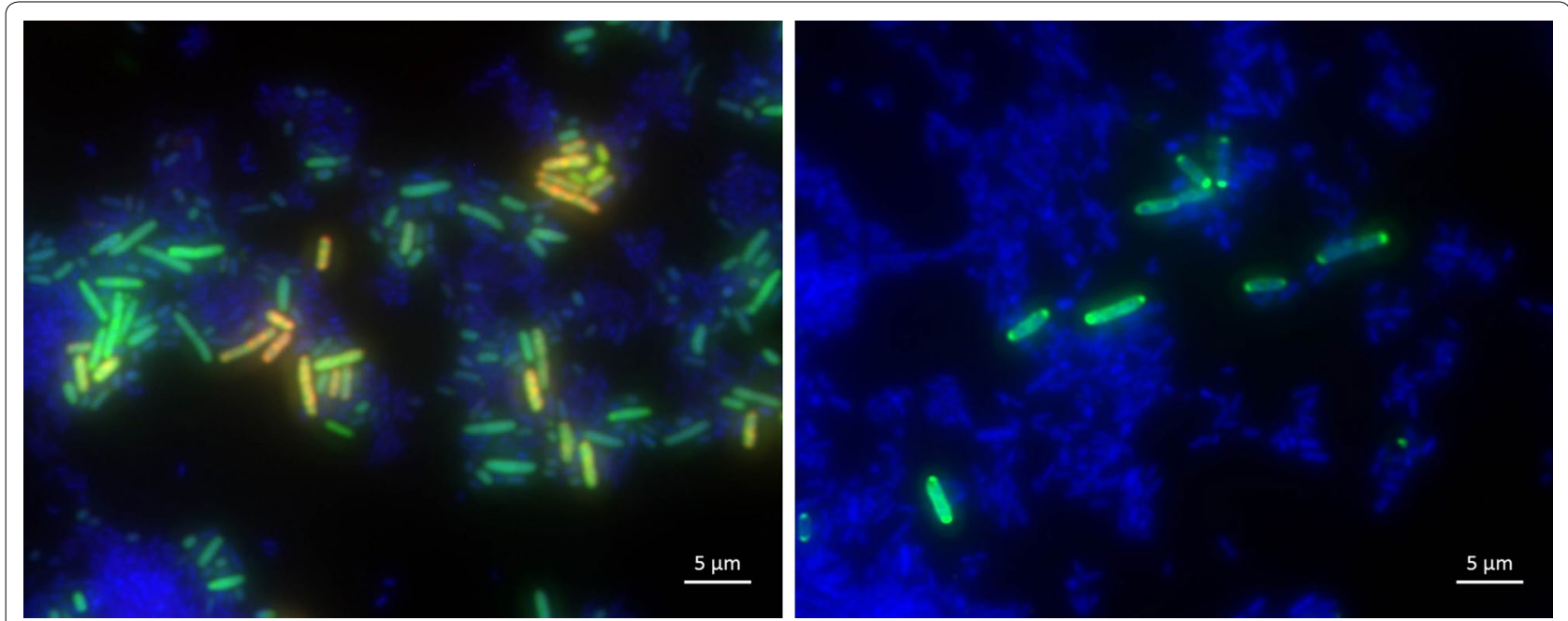

Fig. 3 Detection of resistance in mixed microbial samples. Left FISH staining of TEM $\beta$-lactamase mRNA in resistant E. coli (red), ribosomal RNA staining of all Enterobacteriaceae (green) and DNA/DAPI staining of all bacteria in the sample. Right Antibody staining of TEM $\beta$-lactamases expressing $E$. coli (green) and DNA/DAPI staining of all bacteria in the sample

Table 2 Comparison of culture-independent techniques applied for the screening of antibiotic resistance

\begin{tabular}{llll}
\hline Detection method & FISH & Immunofluorescence & Nitrocefin assay \\
\hline Target & mRNA & Protein & Enzymatic activity \\
Speed $(\mathrm{h})$ & 5 & 7 & $<1$ \\
Costs & Moderate & Moderate/high & Low \\
Simultaneous species identification & Possible & Possible & Not possible \\
Specificity & Narrow, type-specific (e.g. TEM) & Narrow, type-specific (e.g. TEM) & Broad \\
Drawbacks & $\begin{array}{l}\text { Transcription is no correlate for efficient } \\
\text { expression }\end{array}$ & Specific antibodies required & Not suitable on the single cell level \\
& & \\
\hline
\end{tabular}

FISH assays employing up to 50 probes per target mRNA are able to effectively detect groups of related gene products. Efficient detection of mRNAs has been previously performed by RT-PCR; the additional advantage of FISH, however, lies in the detection of resistance on the single cell level, enabling refined insights in multi-species mixed communities and samples. Recently, we developed an extensive set of free-combinable FISH probes targeting the rRNA of various pathogenic bacteria [22]. The assay presented here is a valuable enhancement of these tests. Convenient mRNA FISH assays are not only conceivable to screen for antibiotic resistance elements but are also promising tools to identify the transcription of toxins and other virulence factors. In contrast to the detection by antibodies, mutations are unlikely to affect the detection via FISH, since the use of 50 probes or more tolerates hybridization failure of a few probes. However, monitoring the transcription has the least biological relevance and does neither prove efficient translation nor sufficient biological effectivity.

\section{Conclusions}

Fluorescence in situ hybridization and immunofluorescence tests represent promising and affordable tools for susceptibility testing on the single cell level. They combine the speed of other rapid and culture-independent methods with the ability of the cultural methods to obtain functional information and, furthermore, have the potential for simultaneous species identification.

\section{Additional files}

Additional file 1: Figure S1. Specificity testing of the mRNA FISH assay. Additional file 2: Figure S2. Specificity testing of the immunofluorescence assay.

Additional file 3: Table S1. Examined environmental E. coli isolates with TEM-mediated ampicillin resistance.

Additional file 4: Figure S3. Detection of ß-lactamase activity by the nitrocefin assay. 


\section{Abbreviations}

FISH: fluorescence in situ hybridization; PCR: polymerase chain reaction; RNA: ribonucleic acid; $m R N A$ : messenger RNA; rRNA: ribosomal RNA; RT-PCR: reverse transcription $P C R ; A M P r$ : ampicillin resistance; $T E T^{r}$ : tetracycline resistance; $\mathrm{CHL}^{\text {r: }}$ chloramphenicol resistance; MIC: minimal inhibitory concentration; Y. pseudotuberculosis: Yersinia pseudotuberculosis; E. coli: Escherichia coli; K. pneumoniae: Klebsiella pneumoniae; Y. enterocolitica: Yersinia enterocolitica; LB: lysogeny broth; PBS: phosphate-buffered saline; DAPI: 4',6-diamidino-2-phenylindole; DMSO: dimethyl sulfoxide; ATCC: American Type Culture Collection.

\section{Authors' contributions}

$A R, J A H$ and SAD designed the study. AR carried out the experiments and analyzed the data. AR, JAH and SAD drafted the manuscript. All authors read and approved the final manuscript.

\section{Author details}

${ }^{1}$ Department of Biological Safety, Federal Institute for Risk Assessment, Diedersdorfer Weg 1, 12277 Berlin, Germany. ${ }^{2}$ Department of Biology, Chemistry and Pharmacy, Free University Berlin, Takustr. 3, 14195 Berlin, Germany.

\section{Acknowledgements}

Not applicable.

\section{Competing interests}

The authors declare that they have no competing interests.

\section{Availability of data and materials}

All data supporting the conclusions of this article are incorporated in this manuscript and in its supplementary information files.

\section{Funding}

This work was supported by a grant of the German Federal Ministry of Education and Research and was executed within the framework of the project ZooGloW (FKZ 13N12697). The funders had no role in study design, data collection and interpretation, or the decision to submit the work for publication.

\section{Received: 29 February 2016 Accepted: 13 September 2016}

Published online: 23 September 2016

\section{References}

1. Paphitou NI. Antimicrobial resistance: action to combat the rising microbial challenges. Int J Antimicrob Agents. 2013;42(Suppl):S25-8.

2. Arias CA, Murray BE. Antibiotic-resistant bugs in the 21 st century-a clinical super-challenge. N Engl J Med. 2009;360:439-43.

3. Acar JF, Moulin G. Integrating animal health surveillance and food safety: the issue of antimicrobial resistance. Rev Sci Tech. 2013:32:383-92.

4. Johnson AP. Surveillance of antibiotic resistance. Philos Trans R Soc Lond B Biol Sci. 2015;370:1-12.

5. Moyaert H, de Jong A, Simjee S, Thomas V. Antimicrobial resistance monitoring projects for zoonotic and indicator bacteria of animal origin: common aspects and differences between EASSA and EFSA. Vet Microbiol. 2014;171:279-83.

6. Fluit AC, van der Bruggen JT, Aarestrup FM, Verhoef J, Jansen WT. Priorities for antibiotic resistance surveillance in Europe. Clin Microbiol Infect. 2006;12:410-7.

7. Frickmann H, Masanta WO, Zautner AE. Emerging rapid resistance testing methods for clinical microbiology laboratories and their potential impact on patient management. Biomed Res Int. 2014;2014:1-18.

8. Raj A, van den Bogaard P, Rifkin SA, van Oudenaarden A, Tyagi S. Imaging individual mRNA molecules using multiple singly labeled probes. Nat Methods. 2008;5:877-9.
9. Skinner SO, Sepúlveda LA, Xu H, Golding I. Measuring mRNA copy number in individual Escherichia coli cells using single-molecule fluorescent in situ hybridization. Nat Protoc. 2013;8:1100-3.

10. So LH, Ghosh A, Zong C, Sepúlveda LA, Segev R, Golding I. General properties of transcriptional time series in Escherichia coli. Nat Genet. 2011:43:554-60.

11. Trebesius K, Panthel K, Strobel S, Vogt K, Faller G, Kirchner T, Kist M, Heeseman J, Haas R. Rapid and specific detection of Helicobacter pylori macrolide resistance in gastric tissue by fluorescent in situ hybridisation. Gut. 2000;46:608-14.

12. Haas M, Essig A, Bartelt E, Poppert S. Detection of resistance to macrolides in thermotolerant Campylobacter species by fluorescence in situ hybridization. J Clin Microbiol. 2008;46:3842-4.

13. Hujer AM, Keslar KS, Dietenberger NJ, Bethel CR, Endimiani A, Bonoma RA. Detection of SHV beta-lactamases in Gram-negative bacilli using fluorescein-labeled antibodies. BMC Microbiol. 2009:9:1-4.

14. Kaase M, Lenga S, Friedrich S, Szabos F, Sakinc T, Kleine B, Gatermann SG. Comparison of phenotypic methods for penicillinase detection in Staphylococcus aureus. Clin Microbiol Infect. 2008;14:614-6.

15. Papanicolaou GA, Medeiros AA. Discrimination of extended-spectrum beta-lactamases by a novel nitrocefin competition assay. Antimicrob Agents Chemother. 1990;34:2184-92.

16. Corvec S, Caroff N, Espaze E, Marraillac J, Drugeon H, Reynaud A. Comparison of two RT-PCR methods for quantifying ampC specific transcripts in Escherichia coli strains. FEMS Microbiol Lett. 2003;228:187-91.

17. Dumas JL, van Delden C, Perron K, Köhler T. Analysis of antibiotic resistance gene expression in Pseudomonas aeruginosa by quantitative realtime-PCR. FEMS Microbiol Lett. 2006;254:217-25

18. Fu Y, Zhang F, Zhang W, Chen X, Zhao Y, Ma J, Bao L, Song W, Ohsugi T, Urano T, Liu S. Differential expression of bla (SHV) related to susceptibility to ampicillin in Klebsiella pneumoniae. Int J Antimicrob Agents. 2007;29:344-7.

19. Evans PD, Cook SN, Riggs PD, Noren CJ. LITMUS: multipurpose cloning vectors with a novel system for bidirectional in vitro transcription. Biotechniques. 1995;19:130-5.

20. Covarrubias L, Cervantes L, Covarrubias A, Soberon X, Vichido I, Blanco A, Kupersztoch-Portnoy YM, Bolivar F. Construction and characterization of new cloning vehicles. V. mobilization and coding properties of pBR322 and several deletion derivatives including pBR327 and pBR328. Gene. 1981;13:25-35

21. Vieira J, Messing J. The pUC plasmids, an M13mp7-derived system for insertion mutagenesis and sequencing with synthetic universal primers. Gene. 1982;19:259-68.

22. Rohde A, Hammerl JA, Al Dahouk S. Detection of foodborne bacterial zoonoses by fluorescence in situ hybridization. Food Control. 2016;69:297-305.

23. Bohnert J, Hübner B, Botzenhart K. Rapid identification of Enterobacteriaceae using a novel $23 \mathrm{~S}$ rRNA-targeted oligonucleotide probe. Int J Hyg Environ Health. 2000;203:77-82.

24. Rohde A, Hammerl JA, Appel B, Dieckmann R, Al Dahouk S. FISHing for bacteria in food-a promising tool for the reliable detection of pathogenic bacteria? Food Microbiol. 2015;46:395-407.

\section{Submit your next manuscript to BioMed Central and we will help you at every step:}

- We accept pre-submission inquiries

- Our selector tool helps you to find the most relevant journal

- We provide round the clock customer support

- Convenient online submission

- Thorough peer review

- Inclusion in PubMed and all major indexing services

- Maximum visibility for your research

Submit your manuscript at www.biomedcentral com/submit 